
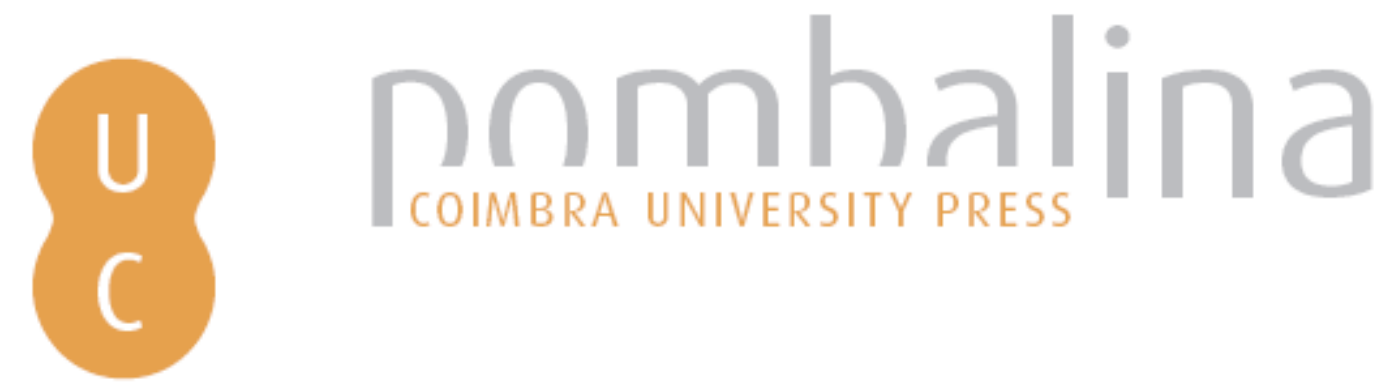

\title{
Responsabilidade dos cientistas na comunicação do risco em situações de emergência: o caso da sentença de L'Aquila
}
Autor(es):
Almeida, António Betâmio de
Publicado por: Imprensa da Universidade de Coimbra; RISCOS - Associação
Portuguesa de Riscos, Prevenção e Segurança
URL persistente:
URI:http://hdl.handle.net/10316.2/34958
DOI:
DOI:http://dx.doi.org/10.14195/978-989-96253-3-4_158
Accessed : $\quad$ 26-Apr-2023 13:46:47

A navegação consulta e descarregamento dos títulos inseridos nas Bibliotecas Digitais UC Digitalis, UC Pombalina e UC Impactum, pressupõem a aceitação plena e sem reservas dos Termos e Condições de Uso destas Bibliotecas Digitais, disponíveis em https://digitalis.uc.pt/pt-pt/termos.

Conforme exposto nos referidos Termos e Condições de Uso, o descarregamento de títulos de acesso restrito requer uma licença válida de autorização devendo o utilizador aceder ao(s) documento(s) a partir de um endereço de IP da instituição detentora da supramencionada licença.

Ao utilizador é apenas permitido o descarregamento para uso pessoal, pelo que o emprego do(s) título(s) descarregado(s) para outro fim, designadamente comercial, carece de autorização do respetivo autor ou editor da obra.

Na medida em que todas as obras da UC Digitalis se encontram protegidas pelo Código do Direito de Autor e Direitos Conexos e demais legislação aplicável, toda a cópia, parcial ou total, deste documento, nos casos em que é legalmente admitida, deverá conter ou fazer-se acompanhar por este aviso.

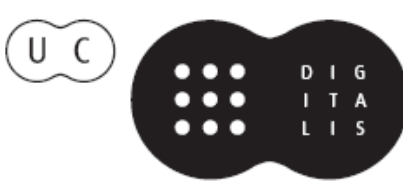



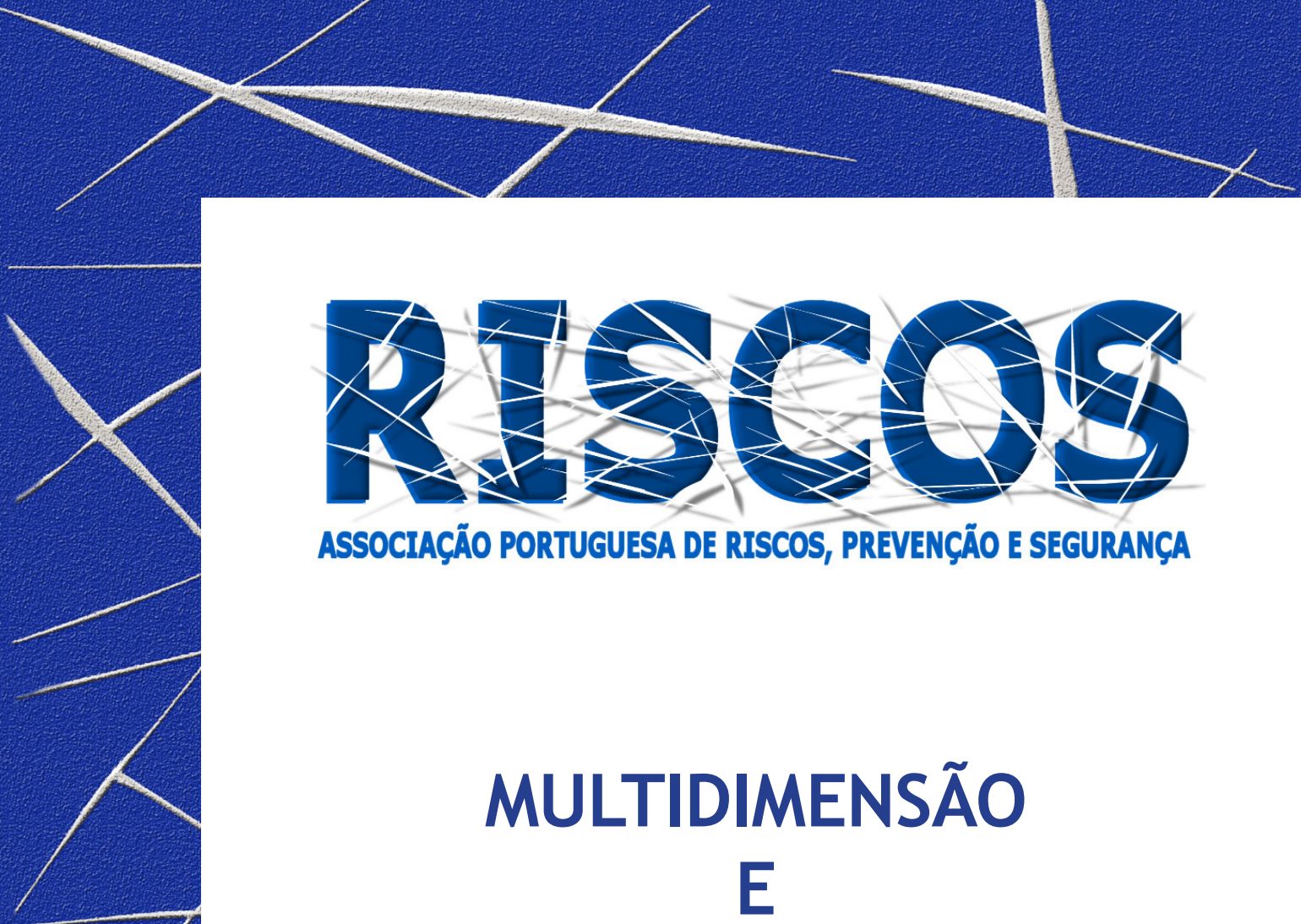

ASSOCIAÇÃO PORTUGUESA DE RISCOS, PREVENCCÃO E SEGURANÇA

MULTIDIMENSÃO

E
TERRITÓRIOS DE RISCO

III Congresso Internacional

I Simpósio Ibero-Americano

VIII Encontro Nacional de Riscos

Guimarães

2014 


\title{
RESPONSABILIDADE DOS CIENTISTAS NA COMUNICAÇÃO DO RISCO EM SITUAÇÕES DE EMERGÊNCIA. O CASO DA SENTENÇA DE L'AQUILA
}

\author{
António Betâmio de Almeida \\ CEHIDRO, Instituto Superior Técnico da Universidade de Lisboa \\ betamio.almeida@ist.utl.pt
}

\begin{abstract}
RESUMO
A responsabilidade ética de especialistas na comunicação de riscos públicos e no apoio a decisões em situações de emergência é uma questão pertinente. Salientam-se as intervenções associadas a potenciais eventos naturais (cheias, ciclones, secas...) ou acidentes tecnológicos (poluição, rotura de barragem...). A sentença e o processo de L'Aquila (Itália) suscitam a reflexão sobre este assunto. Em 2012, sete cientistas italianos foram condenados a pesadas penas de prisão por terem sido considerados responsáveis pela morte de pessoas no sismo que ocorreu na cidade de L'Aquila, em Abril de 2009. A acusação considerou que a comunicação ao público relativa ao risco sísmico, alguns dias antes do sismo, foi incompleta, imprecisa e contraditória tendo contribuído decisivamente para modificar a percepção de perigo das vítimas e para alterar os respectivos procedimentos de protecção. 0 presente artigo tem o objectivo principal de apresentar uma análise muito sumária do processo e o respectivo impacto na relação entre cientistas, a protecção civil e o público, em situações de crise.
\end{abstract}

Palavras-chave: comunicação, responsabilidade, risco, processo de L'Aquila.

\section{Introdução}

Integrado num órgão da Protecção Civil, um consultor, cientista ou especialista, emite, através de um canal de televisão, uma recomendação para o público desvalorizando ou negando a possibilidade de ocorrência iminente de um acontecimento perigoso. Uma parte da população segue essa indicação e não aplica as medidas de protecção usuais nessas circunstâncias. 0 evento ocorre e há vítimas. Qual é a responsabilidade do referido consultor?

Este é o problema em análise.

No processo de gestão do risco público, a comunicação é um dos componentes mais delicados e com efeitos incertos e potencialmente graves. No contexto de uma crise, a comunicação pode tornar-se crítica. É o caso de situações de difícil controlo nas quais as medidas de protecção podem envolver uma grande perturbação social, nomeadamente quando exigem a evacuação de populações em áreas extensas como é o caso da ameaça de eventual ocorrência de um sismo ou de um tsunami ...

O nível de incerteza epistémica pode ser elevado e impedir uma opinião científica conclusiva. É, então, frequente que as autoridades responsáveis pela protecção civil e os órgãos de comunicação social solicitem a cientistas e técnicos especialistas que emitam publicamente opiniões sobre o assunto.

A sentença proferida por um tribunal relativamente à comunicação do risco nas vésperas do sismo que atingiu, em 2009, a cidade italiana de L'Aquila veio suscitar a necessidade de uma reflexão ponderada sobre esta matéria. Uma descrição detalhada do caso pode encontrar-se em Almeida e Oliveira (2014).

A incerteza e a liberdade científicas têm justificado que o acerto das opiniões emitidas e os respectivos impactos não sejam objecto de qualquer responsabilização legal: a autonomia e a colaboração dos cientistas assim o aconselham. Contudo, afigura-se ser oportuna uma reflexão 
sobre os melhores procedimentos a seguir em situações semelhantes nomeadamente quando há uma situação de emergência com elevado impacto potencial, incerteza na previsão e grande repercussão social das mensagens emitidas por especialistas.

\section{O processo de L'Aquila}

Em Outubro de 2012, um tribunal italiano condenou sete cientistas a seis anos de prisão por terem sido considerados responsáveis por morte e ferimentos de pessoas no sismo que ocorreu no dia 6 de Abril de 2009. Recorda-se que este sismo provocou a morte de 309 pessoas e ferimentos a cerca de 1500 pessoas, e 67500 deslocados para além de avultados prejuízos materiais. A sentença do tribunal fixou a referida pena de prisão acrescida de outras medidas (e.g. nove milhões de euros de indemnizações). A defesa pediu recurso pelo que se aguarda a conclusão do processo. 0 estudo do processo foi feito com base no documento"Requisitória Scritta del Publico Ministero" (do Procurador Público da República) de 25 de Setembro de 2012 (509 p.) e na audição da gravação das sessões do tribunal.

Os acusados eram membros de uma Comissão Nacional para a previsão e prevenção dos riscosrelevantes, a "Comissione sui Grandi Rischi”, que fazia parte do sistema de protecção civil italiano. Foram acusados de culpa, na forma de negligência, imprudência e incompetência, pelo seu comportamento associado à reunião extraordinária da Comissão que teve lugar no dia 31 de Março de 2009, com “...o objectivo de... fazer um exame cuidadoso dos aspectos científicos e de protecção civil relativos à sequência sísmica...na província de L'Aquila”. Na realidade, a população e as autoridades tinham uma preocupação dominante: a persistente ocorrência de abalos sísmicos. De acordo com o Procurador, as declarações a órgãos da comunicação social foram incompletas, imprecisas e contraditórias (e até levianas) tendo modificado a percepção dos cidadãos e das autoridades locais sobre o risco sísmico: as vítimas teriam alterado o modo habitual de protecção em resultado das declarações da referida Comissão.

No tribunal foi defendido que os responsáveis pela comunicação de riscos estariam sujeitos a uma responsabilização social e judicial pelas recomendações ao público, numa situação de crise. A sentença provocou uma reacção muito forte por parte de organizações científicas internacionais. Com efeito, considerou-se, incorrectamente, que os cientistas teriam sido acusados por terem falhado a previsão do terramoto. Esta interpretação, na opinião do autor, não é fundamentada mas influenciou muitos dos protestos. O Procurador salientou que a acusação não se dirigia à actividade científica dos acusados no domínio da previsão de sismos mas sim à comunicação sobre os riscos que deveria ter sido mais explícita por forma a permitir aos cidadãos fazer opções adequadas.

A sentença parece ser muito desproporcionada e injusta. Com efeito, não parece ser possível demonstrar que, se a comunicação da Comissão tivesse sido menos ambígua, as vítimas em causa no processo teriam tido outra sorte. Os acusados merecem, nesta perspectiva, as manifestações de solidariedade.

\section{Uma reflexão que se justifica}

A sentença e o processo de L'Aquila suscitam a reflexão sobre algumas questões relevantes para uma gestão de emergências mais eficaz e sobre as potenciais responsabilidades dos intervenientes na comunicação com o público exposto ao risco.

O Governo de Itália, consciente da importância de alguns aspectos associados ao sismo de 2009, promoveu (Maio de 2009) a constituição de um grupo internacional de 10 especialistas em 
sismologia (Comissão Internacional de Previsão de Terramotos para a Protecção Civil - ICEF). Este grupo tinha como missão a avaliação do conhecimento científico actual relativo à previsão de curto-prazo de sismos tectónicos e a elaboração de recomendações para orientação da protecção civil. O relatório final, publicado em 2011, apresenta um conjunto de recomendações práticas: a comissão de especialistas deveria reportar directamente às autoridades (e não directamente à comunicação social); a comunicação deveria ser baseada em princípios da ciência social e em previsões probabilísticas.

A American Geophysical Union realizou, em Dezembro de 2012, uma sessão especial na qual foram apresentados e discutidos os desafios colocados por este caso: AGU Fall Meeting, 3-7 Dezembro de 2012, São Francisco (E.U.A.), Sessão Especial sobre L'Aquila (“Communicating Geohazard Risk Assessments: Lessons Learned From the Verdicts in the L'Aquila Earthquake Case") na qual foram oradores Thomas Jordan, Max Wyss e Stephen Sparks (existe um vídeo da sessão na Internet).

Nesta reunião foram considerados relevantes os aspectos científicos e técnicos, relativos à previsão a curto prazo de acontecimentos sísmicos, os aspectos operacionais associados à comunicação do risco em situação de crise, os aspectos jurídicos associados à eventual responsabilização penal dos cientistas ou especialistas por afirmações associadas à previsão e comunicação de riscos, e os aspectos éticos e políticos associados à actuação de cientistas, na qualidade de especialistas, em grupos de trabalho ou comissões oficiais de apoio a autoridades.

Uma comunicação para o público baseada nas incertezas científicas de carácter aleatório (utilizando probabilidades ou terminologia equivalente) ou de carácter epistémica (eventualmente através de probabilidades construídas ou por outros meios) implica técnicas especiais de comunicação por forma a evitar ambiguidades. Como se sabe, a caracterização probabilística, na quase totalidade dos casos, não é assertiva e não afasta definitivamente as alternativas em causa: mesmo uma probabilidade de $90 \%$ que não ocorra, nos próximos dias, um evento não é contraditória com essa ocorrência.

Diz a experiência que esta particularidade tende a afastar a descrição probabilística da comunicação: em determinadas situações, nomeadamente quando são entrevistados em directo, muitos especialistas são provocados a emitirem afirmações definitivas, por vezes precipitadas. Diga-se, em abono da verdade, que uma certa vertigem para a simplificação ou para uma demonstração de sabedoria sem incertezas é frequente em algumas afirmações de cientistas em órgãos de comunicação social (comportamento que muitas vezes está associado a um elevado orgulho pessoal ou mesmo a vaidade). Em L'Aquila parece que tal ocorreu. Os órgãos de comunicação tendem a apreciar essas afirmações sem dúvidas.

Acresce que o prestígio da ciência junto da opinião pública é muito elevado em resultado dos muitos sucessos conhecidos nos mais variados domínios. Daqui resulta que uma orientação dada por um especialista, investigador ou professor universitário, pode ter uma credibilidade muito grande. Admite-se que os responsáveis de serviços de protecção civil dos diferentes países também assim o possam considerar. Nesta conformidade, é muito natural que um consultor independente, e não enquadrado numa organização oficial da protecção civil, seja chamado a prestar, numa situação de crise, declarações importantes à comunicação social que podem ter efeitos não controláveis ou motivar decisões erradas ou precipitadas por parte de cidadãos. 


\section{Conclusões}

A análise e a reflexão suscitadas pelo processo de L'Aquila colocam, assim, alguns desafios à comunidade científica e aos serviços de protecção civil:

- Em situação de crise, quais são os modos aconselháveis de comunicar situações de risco associadas a uma forte incerteza científica? Quando é que é pertinente e aconselhável utilizar um discurso baseado em probabilidades e de que modo essa informação deve ser elaborada para ser entendida por leigos e proporcionar uma percepção mais correcta da situação?

- Que tipo de “protocolo" deve ser seguido em situações de crise para proporcionar uma comunicação mais eficaz e segura para o público? Que tipo de precaução deve ser transmitida ao público para que este tenha consciência das incertezas envolvidas?

- Quais são as recomendações genéricas aos especialistas e técnicos no que respeita a responsabilidade (pessoal, civil e institucional) resultante de afirmações públicas no contexto da comunicação do risco e de medidas de protecção pessoais?

- Como deveremos encarar a responsabilidade social e política de comissões consultivas de especialistas, de apoio a autoridades políticas ou administrativas, em particular num contexto de riscos públicos e de situações de crise?

O apoio dos cientistas é fundamental, mas a relação comunicacional com o público (sobretudo em momentos cruciais) deve ser mediada por uma entidade apropriada ou sujeita a uma preparação muito cuidada. Há que evitar que, face ao receio de ser constituído arguido, os consultores da protecção civil evitem emitir opiniões ou sejam excessivamente prudentes. No caso do processo de L'Aquila, há a referir que os cientistas podem ter sido (foram) vítimas do sucesso da Ciência, do prestígio social adquirido e do reconhecimento deste estatuto por parte da sociedade e dos políticos: uma mensagem transmitida pessoalmente por um cientista especialista na situação é muito mais convincente do que por um funcionário ou por um político local ou nacional, em particular quando essa mensagem sugere a "não-acção".

Salienta-se que o processo de L'Aquila tem particular importância em países como Portugal que têm zonas de alto risco sísmico incluindo áreas urbanas antigas e muito populosas. Assim, este processo judicial deve merecer a melhor atenção por parte das entidades nacionais competentes e pela comunidade científica.

\section{Bibliografia}

Almeida, A. B. e Oliveira, C.S. (2014) - “O Caso da Sentença de L'Aquila. Responsabilidade na Comunicação do Risco", Revista PROCIV (ANPC), № 73, Abril, Lisboa, pp.6-10. 